NBER WORKING PAPER SERIES

\title{
THE EFFECT OF THE 1998 MASTER SETTLEMENT AGREEMENT ON PRENATAL SMOKING
}

\author{
Douglas E. Levy \\ Ellen Meara \\ Working Paper 11176 \\ http://www.nber.org/papers/w11176 \\ NATIONAL BUREAU OF ECONOMIC RESEARCH \\ 1050 Massachusetts Avenue \\ Cambridge, MA 02138 \\ March 2005
}

We gratefully acknowledge financial support from the Agency for Health Care Research and Quality (Levy), the National Institute of Aging (Levy) and the Russell Sage Foundation (Meara). We thank Joseph P. Newhouse, Alan M. Zaslavsky, and Karen M. Kuntz for their valuable input during the evolution of this study; A. James O'Malley for statistical guidance; and Arnold M. Epstein for comments on an earlier draft of this manuscript. The views expressed herein are those of the author(s) and do not necessarily reflect the views of the National Bureau of Economic Research.

(C) 2005 by Douglas E. Levy and Ellen Meara. All rights reserved. Short sections of text, not to exceed two paragraphs, may be quoted without explicit permission provided that full credit, including $(\odot)$ notice, is given to the source. 
The Effect of the 1998 Master Settlement on Prenatal Smoking

Douglas E. Levy and Ellen Meara

NBER Working Paper No. 11176

March 2005

JEL No. I12, I18

\section{ABSTRACT}

The Master Settlement Agreement (MSA) between the major tobacco companies and 46 states created an abrupt 45 cent (21\%) increase in cigarette prices in November, 1998. Earlier estimates of the elasticity of prenatal smoking implied that the price rise would reduce prenatal cigarette smoking by $7 \%$ to $21 \%$. Using birth records on 10 million U.S. births between January 1996 and February 2000, we examined the change in smoking during pregnancy and conditional smoking intensity in response to the MSA. Overall, adjusting for secular trends in smoking, prenatal smoking declined much less than predicted in response to the MSA.

Douglas E. Levy

Department of Health Policy and Management

Harvard School of Public Health

677 Huntington Avenue, $4^{\text {th }}$ Floor

Boston, MA 02115

douglas_levy@post.harvard.edu

Ellen Meara

Department of Health Care Policy

Harvard Medical School

180 Longwood Avenue

Boston, MA 02115

and NBER

meara@hcp.med.harvarde.edu 


\section{Introduction}

On November $23^{\text {rd }}, 1998$, the attorneys general for 46 states suing the major United States tobacco companies reached the Master Settlement Agreement (MSA) with the defendants who agreed to pay the states $\$ 206$ billion (Capehart, 2001). To finance the settlement, tobacco companies immediately increased cigarette prices by 45 cents $(21 \%)$ nationwide (Capehart, 2001). Cigarette prices rose another 42 cents over the following two years. The rise in prices constitutes the most important smoking-related consequence of the MSA (Cutler et al., 2002; Schroeder, 2004). We examine the effect on prenatal smoking of the unprecedented increase in cigarette prices following the MSA.

Two decades of research suggests that raising cigarette prices is an effective means of reducing population smoking prevalence. Estimates of the price elasticity of smoking participation range from -0.15 to -0.26 (Lewitt and Coate, 1982; Wasserman et al., 1991; Hu et al., 1995; Farrelly and Bray, 1998). Specific populations, however, are known to be more or less price sensitive (Chaloupka and Warner, 2000). Studies of pregnant women suggest that the price elasticity of prenatal smoking participation is substantially higher than in the general population, with estimates typically greater than -0.35 (Evans and Ringel, 1999; Gruber and Köszegi, 2001; Gruber and Zinman, 2001; Ringel and Evans, 2001; Bradford, 2003; Colman et al., 2003), and even as high as -1.83 (Lien and Evans, 2004).

Evidence of smokers' price responsiveness has made raising excise taxes a common policy lever for reducing cigarette smoking. Between 1990 and 1998, the average retail price of a pack of cigarettes rose from $\$ 1.53$ to $\$ 2.18$ and state and federal excise taxes combined increased from an average of $\$ 0.39$ to $\$ 0.63$ (Orzechowski and Walker, 2003). The MSA provides an opportunity to examine how a large, nationwide price increase affects prenatal smoking 
compared with the incremental changes in cigarette prices seen during the years preceding the MSA.

Prenatal smoking is the most important modifiable risk factor associated with low birth weight (LBW; <2500g), contributing to an estimated 20\% of LBW births (USDHHS, 1990). On average, prenatal smoking is estimated to raise the odds of LBW by $20-230 \%$, depending on prenatal smoking intensity (USDHHS, 2001). Because over 520,000 babies are born annually to women who smoke during pregnancy, changes in prenatal smoking warrant scrutiny in any evaluation of the overall health impact of the MSA.

In this paper, we use data from the National Vital Statistics System's Natality Detail File to examine the effect of the MSA and its immediate 45 cent price increase on prenatal smoking participation and conditional intensity of smoking for pregnant smokers. We compared smoking related outcomes before and after the MSA and we estimated relative price regressions that exploited the wide variation in the relative price change following the MSA to measure the change in prenatal smoking behavior following the MSA. The majority of price elasticity estimates suggest that the immediate price shock from the MSA would reduce prenatal smoking by at least $7.4 \%$. In the medium run, given an additional 42 cent price rise over the following two years that is likely to be attributable, in part, to the MSA, one should expect an even larger decline in prenatal smoking participation.

Overall, pregnant women responded much less than expected to this unprecedented increase in the price of cigarettes. Compared with the level of prenatal smoking participation predicted by the secular trends leading up to the MSA, pregnant women reduced smoking by less than $3 \%$. Teenage mothers were the most responsive group, reducing smoking by just over $8 \%$ 
compared to that predicted by secular trends leading up to the MSA. The relative price models yield no evidence of price responsiveness among our sample of pregnant women.

The remainder of the paper will proceed as follows: in section 2, we describe in detail the previous literature on cigarette prices and prenatal smoking; in section 3, we outline our empirical specification for estimating the effect of the MSA net of secular trends during this time period; in section 4 we present the results of our analysis of smoking trends before and after the MSA, including two tests to determine whether our results are robust to important assumptions in our specifications; in section 5 we describe and present estimates of the effect of differential relative price changes on prenatal smoking behavior; and in section 6 we compare our estimates to the prior literature and discuss potential explanations for the smaller than expected price response.

\section{Prior Research on Price Responsiveness and Prenatal Smoking}

Recent research on the response of pregnant women to cigarette price changes has yielded disparate estimates of prenatal smoking elasticities (Evans and Ringel, 1999; Gruber and Köszegi, 2001; Gruber and Zinman, 2001; Ringel and Evans, 2001; Bradford, 2003; Colman et al., 2003; Lien and Evans, 2004). In the earliest such study, Evans and Ringel (1999) estimate the price elasticity of prenatal smoking participation to be -0.50 by using a sample of 10.5 million birth records from the Natality Detail Files to identify the response of pregnant women to within-state variation in excise taxes between 1989 and 1992. In a closely related article using the same data for years 1989-1995, Ringel and Evans (2001) estimate that the overall price elasticity of prenatal smoking participation is -0.7 and that the price response varies widely by maternal race and education. Their findings suggest that the groups who would respond least to a 
tax change would be teenage mothers, Hispanic mothers, and those with less education. Both of these studies exploit variation stemming from relatively modest cigarette tax changes, and thus their elasticity estimates should be viewed as most reliable for predicting the response to relatively small price changes. In a complement to this earlier work, Lien and Evans (2004), again use the Natality Detail Files to evaluate changes in prenatal smoking in response to large tax changes (between 14 and 50 cents ) in four states during 1993 and 1994. These estimates yield state-specific prenatal smoking participation elasticities ranging from -0.10 in Illinois to 1.83 in Massachusetts. Gruber and Köszegi (2001) and Gruber and Zinman (2001) estimated prenatal smoking participation elasticities of -0.35 for pregnant women and -0.38 for pregnant teenagers using Natality Detail Files from 1991-1997 and 1989-1996, respectively. Both of these models use the same data as Evans and Ringel's earlier work, and a similar specification identifying the price effect based on changes in excise taxes. Using data from the National Maternal and Infant Health Survey of 1988 and its 1991 follow-up survey, Bradford (2003) finds a similar participation elasticity among pregnant women, -0.35 . Notably, he finds no significant difference between pregnant and non-pregnant women in the elasticity of smoking participation. In related, but not directly comparable work, Colman et al. (2003) explicitly model the quitting behavior of women smoking at the time of conception. Using the PRAMS database on 10 states from 1993 to 1999, they estimate a price elasticity of quitting during pregnancy of about -1.0.

Despite a growing body of work in this area, there is no consensus regarding the elasticity of smoking during pregnancy, and little evidence on how these elasticities vary by the characteristics of the mothers. This ambiguity in the literature leaves gaps in knowledge about the potential effectiveness of excise taxes or other price-related policy tools to reduce prenatal smoking. The MSA provides a useful natural experiment that allows us to test the elasticity of 
prenatal smoking during a recent time period, and in response to a large national price change. The MSA allows us to ask, does a large price increase (over 21\%) change the smoking behavior of pregnant women in the late 1990s, and if so, how does the price elasticity of smoking (participation and intensity) vary by demographic characteristics?

\section{Empirical Methods}

We examined trends in prenatal smoking before and after the MSA, allowing for changes in both the level and the trend in prenatal cigarette smoking at the time of the MSA. We estimate an implied elasticity based on this overall pre-post MSA specification.

\section{The MSA as a Natural Experiment}

The MSA created a natural experiment by subjecting the United States' population to a sudden, 45 cent per pack increase in cigarette prices. As discussed more fully in Cutler et al. (2002), the factors leading to the settlement and the subsequent price rise had more to do with the legal environment and the tobacco companies' fears of a large award and future litigation than with a sudden, discrete change in smoking attitudes. To show the abrupt nature of the price change, Figure 1 presents the average annual retail price of a pack of cigarettes (including excise taxes and adjusted for inflation to 1999 dollars) from late 1995 to early 2000 (Orzechowski and Walker, 2003). Monthly retail price data are unavailable, so we also present monthly wholesale prices (USDA, 2004), (including excise taxes but excluding generic brands) to illustrate the sharp increase in prices following the November 1998 MSA. The monthly wholesale prices demonstrate the abrupt price change we use to identify pregnant women's response to the MSA. The figure also clearly demonstrates how average retail prices continued to rise in the two years 
following the MSA. We compare the rate of prenatal smoking and the trend in this rate before and after the MSA, attributing only the immediate price change (a 45 cent increase in November, 1998) to the MSA since that is the portion of the price change most clearly linked to the settlement. Assuming that any non-price effects of the MSA really do not affect pregnant women during our period of study, we will estimate an upper bound for the price response of pregnant women following the MSA. Our estimate is an upper bound because we attribute changes in behavior to the immediate 45 cent price change that accompanied the MSA, excluding the additional rise in cigarette prices that occurred in the subsequent months.

\section{Data and Sample Characteristics}

Smoking and demographic data were obtained from the 1996-2000 Natality Detail Files (NCHS, 1996-2000). These files, generated from birth records, include all births within the United States during that time period. We restricted the study data to infants conceived between January 1996 and February 1998 and between December 1998 and February 2000, defining conception date using reported gestational age. We excluded conceptions between March 1998 and November 1998 because these pregnancies may have been affected by the MSA for only a portion of their term. We end the study period in February 2000 because infants conceived beyond this date were mostly born in 2001, and we wished to limit our follow-up to a period when the price effects of the MSA would be strongest. In addition to the price change, the MSA stipulated that tobacco companies reduce specific kinds of advertising and allocate a portion of the settlement monies to a foundation funding anti-tobacco advertising, among other things. These other policy changes did not take effect immediately and they likely had little impact on prenatal smoking during our study period (Chaloupka and Warner, 2000; Cutler et al., 2002; 
American Legacy Foundation, 2004), so we ascribe all observed effects of the MSA to the price change.

We restricted the sample to singleton births delivered by mothers aged 15-44. Because California, Indiana, South Dakota, and parts of New York outside of New York City did not report smoking, we excluded these births (20\% of the nation) from our analyses. Records with incomplete birth weight, smoking, and demographic data were excluded.

Of the 10,029,081 singleton births to women 15-44 years old in our study states and time period, 9,638,863 (96\%) had complete data on the outcomes and covariates of interest. Table 1 shows that most single variables had missing data for fewer than $2 \%$ of the observations. Our sample restrictions resulted in a sample of mothers with slightly better outcomes than the complete population of pregnant women. The smoking rate among women in our sample was $12.1 \%$, the median birth weight was $3,374 \mathrm{~g}$, and the rate of LBW was $6.0 \%$ while the smoking rate in the complete population of pregnant women in 1998 was $12.9 \%$ (NCHS, 2003), the median birth weight was 3,350g, and the rate of LBW was 7.6\% (NCHS, 1998). Demographic characteristics for mothers in the pre-MSA period were very similar to those in the post-MSA period, though there were slightly more Hispanic mothers and fewer white mothers in the postMSA period (Table 1).

\section{Empirical Specification}

We estimated the effect of the MSA on two outcomes - prenatal smoking status and conditional smoking intensity (smokers' number of cigarettes smoked per day) - by examining them before and after November 1998. For smoking status, where the outcome is binary, we estimated linear probability models so that the model coefficients would be directly interpretable 
and so that the time trends would be linear on the probability scale. Our large sample size assures that our data sufficiently approximate the assumptions necessary for ordinary least squares regression. Estimates using maximum-likelihood logit models (not reported) were qualitatively and quantitatively similar. We used ordinary least squares models to examine smokers' number of cigarettes smoked per day during pregnancy before and after the MSA.

For each outcome, we estimated models of the following form:

$$
\begin{gathered}
Y_{i s t}=\alpha+\beta_{1} \text { time }_{t}+\beta_{2} \text { PostMSA }_{t}+\beta_{3} \text { time }_{t} * \text { PostMSA }_{t}+\gamma \text { ExciseTaxes }_{s t} \\
+\varphi \text { Maternal Characteristics } \\
\text { ist }+\delta_{1}^{\prime} \text { CalendarMonth }_{t}+\delta_{2}^{\prime} \text { State }_{s}+\varepsilon_{i s t} .
\end{gathered}
$$

To control for secular trends in smoking, the pre-post models included a linear time trend variable, time $_{t}$ spanning the 50 months of our study period. We tested and rejected higher order time trends. In each model, the effect of the MSA was assessed using a binary variable, $\operatorname{PostMSA}_{t}$, equal to 1 for all births conceived after the MSA, to capture changes in the level of the outcomes, and an interaction between $\operatorname{PostMSA}_{t}$ and time ${ }_{t}$ to estimate the change in trend following the MSA. The vector $\delta_{1}$ includes a set of calendar month effects to control for known differences in the composition of births at different times of the calendar year, and the vector $\delta_{2}$ includes a set of state fixed effects to control for time-invariant differences in smoking across states. Our Maternal Characteristics included maternal race, educational attainment, age, parity, prenatal care, marital status, prior preterm birth, alcohol consumption, and infant gender. Each was coded categorically as shown in Table 1. Maternal characteristics, including smoking and alcohol consumption, were self-reported. Race/ethnicity categories were defined by the U.S. Division of Vital Statistics. Finally, we controlled for state and federal excise taxes (Orzechowski and Walker, 2003), adjusted for inflation using the Consumer Price Index, urban consumers series (USDL, 2003). Following several earlier studies, we linked observations in the Natality Detail Files to cigarette excise taxes specific to the infant's month of conception and the 
state where the birth occurred (Evans and Ringel, 1999; Ringel and Evans, 2001; Lien and Evans, 2004).

For each analysis, we modeled outcomes separately for three mutually exclusive racial/ethnic groups (non-Hispanic blacks, non-Hispanic whites and Hispanics), two categories of educational attainment (high school degree or less and greater than a high school degree), and two age groups (15-19 year olds and 20-44 year olds), as price-responsiveness may vary along these dimensions (Farrelly and Bray, 1998; Chaloupka and Pacula, 1999; Chaloupka and Warner, 2000; Ringel and Evans, 2001; USDHHS, 2001). All analyses assumed independence of observations between, but not within states, and standard errors were adjusted to address clustering within states, using methods suggested by Huber and White (White, 1980).

\section{Trends in Prenatal Smoking Before and After the MSA}

\section{Changes in Smoking Prevalence}

Before discussing our regression results, we present raw data on prenatal smoking prevalence during the years before and after the MSA to establish the trends in prenatal smoking leading up to the MSA. Figure 2 displays annual prenatal smoking rates based on published U.S. Vital Statistics data from birth certificates (NCHS, 2004). The figure shows a marked, relatively linear decline in prenatal smoking between 1995 and 2001. This crude look at the data suggests two things. First, our assumption of a linear trend in smoking rates over our study period appears reasonable, a fact confirmed more rigorously in our models when higher order time trends were rejected. Second, there is no discernible break in prenatal smoking trends at the time of the MSA. 
Figure 3 displays raw smoking prevalence from our data as well as predictions from the model of prenatal smoking trends. The dashed line presents the predictions assuming the preMSA trend in prenatal smoking continued unchanged in the period after the MSA. The solid line presents the model predictions based on the actual data following the MSA. It is clear that the model fits the data well and that prenatal smoking following the MSA deviated only slightly from the secular trend established before the MSA.

The left-hand columns in Table 2 give the linear probability model coefficients for the MSA effects, excise taxes, and the demographic covariates on which we ultimately stratified our analysis. The probability of smoking during pregnancy declined by about 0.01 percentage points per month during the period leading up to the MSA, dropped 0.3 percentage points at the time of the MSA, and then continued to decline with no significant change in trend after the MSA. The signs on the other coefficients are all as expected. Smoking declines with age for all mothers over age 20. Smoking is most prevalent among women with some high school education but no degree, and white women are substantially more likely to smoke than blacks, Hispanics, or women of other racial and ethnic groups. These trends are similar for the conditional smoking intensity estimates. Conditional smoking intensity during pregnancy declined by about 0.01 cigarettes/day per month prior to the MSA, dropped another 0.19 cigarettes/day at the time of the MSA, and declined 0.02 cigarettes/day per month after the MSA.

Table 3 shows how smoking behavior changed in relative terms following the MSA. Overall and within most groups, the relative decline in smoking was under 3\%. Mothers aged $15-19$ were the exception to this trend. Their smoking rates declined by $6.32 \% 8$ months after the MSA, and $8.38 \%$ by 15 months after the MSA. These estimates imply an elasticity of smoking prevalence of about -0.13 overall and -0.30 among teenagers, given the $21 \%$ price rise 
at the time of the MSA. These elasticities are lower than the prior estimates based on cigarette excise taxes and using similar data from earlier during the 1990s. Table 4 shows analogous estimates of the relative changes in smoking intensity (among prenatal smokers), and shows comparable, small effects of the MSA. The relative decline in smoking was at or below 3\% within all groups at both 8 and 15 months following the MSA implying conditional smoking elasticities of less than -0.14 .

\section{Testing the Sensitivity of the Time Trend Assumptions}

Because our pre-post analysis lacks a control group, our results rely on the assumption that the secular time trends we estimated in the period before the MSA would continue after November 1998 in the absence of the MSA. To address this potential limitation, we tested the sensitivity of our results to alternative assumptions regarding smoking trends following the MSA. The results above are robust to alternative assumptions regarding the trend in prenatal smoking. Because we estimate relatively small effects of the MSA, any understatement of the secular decline in smoking that would occur absent the MSA would suggest that the true impact of the MSA was smaller than estimated, or near zero. We tested an alternative scenario, where the secular trend in smoking reversed near the time of the MSA. In contrast to the estimated decline in prenatal smoking of 0.12 percentage points per year before the MSA, the true secular trend in smoking would have to be rising 0.33 percentage points per year following the MSA before our estimate of the relative change in prenatal smoking reached $-7.4 \%$, the minimum estimate based on national data in the earlier literature. Figure 2 further emphasizes how dramatic this secular trend would be in light of several years of monotonically declining rates of prenatal smoking in the years leading up to the MSA. 
Specification Check to Test the Assumption of Intertemporal Independence

For computational reasons, we assumed that the $\varepsilon_{i s t}$ were independent between states and across time periods. However, we tested first-order autoregressive models for $\varepsilon_{i s t}$ using generalized least squares regression and data aggregated by state and month to gain insight into how the assumption of intertemporal independence affected our analyses. We modeled the outcomes as a function of the time and MSA variables and compared auto-regressive and independence models. We find that, while we reject the independence assumption, the point estimates for the MSA effects are quite similar in the two models, though the confidence bounds on the effect of the MSA are 1.3 times wider under the autoregressive assumption.

\section{The Effect of Relative Price Changes on Prenatal Smoking}

Any standard economic model of consumer demand implies that the relative size of the price change accompanying the MSA should influence the expected impact of the MSA. The relative change in cigarette prices following the MSA varied widely across states, ranging from under 16\% in Massachusetts to over 30\% in Maryland. We exploit this variation in the relative price change at the time of the MSA.

We estimate models of the change in prenatal smoking in a given state as a function of the relative change in cigarette prices due to the MSA and state excise taxes between fiscal year (FY) 1998 (July 1997 through June 1998) and FY 2000 (July 1999 through June 2000). For these models, the unit of analysis is the 1998 to 2000 change within a given state. To calculate the relative price change during this period for each state, we used FY 1998 retail cigarette prices as the baseline price. Then, for each state, we calculated the total of the change in excise taxes 
between 1998 and 2000 plus a constant 45 cent MSA effect. We used this total to create the following modified 2000 price in each state:

$$
\text { Price }_{2000}{ }^{\prime}=\text { Price }_{1998}+\Delta(\text { excise taxes })_{2000-1998}+45 \text { cents }
$$

Thus, we are calculating the "plausibly exogenous" price change within a state, assuming that the MSA price effect and state excise tax changes at this time are exogenous to underlying, within state trends. Due to the absence of monthly retail price data, we used annual retail prices (Orzechowski and Walker, 2003) and estimated models of the relative change in the state rate of prenatal smoking participation and average conditional smoking intensity as a function of relative price changes. The models take the following form:

$$
\ln \left(\frac{Y_{s, 2000}}{Y_{s, 1998}}\right)=\beta_{1} \ln \left(\frac{\text { Price }_{s, 2000}^{\prime}}{\text { Price }_{s, 1998}}\right)+\varepsilon_{s},
$$

where $s$ indexes state of birth. In this framework, we would expect $\beta_{1}$ to be negative in sign. That is, for a higher relative price rise, we expect a greater relative decline in smoking. We weighted each state-level observation by the total number of births in that state in 1998 and 2000 combined.

We plot each state's relative changes in smoking prevalence and relative price changes in Figure 4. As seen in the scatter plot, and confirmed in our regression models, the impact of relative price changes on prenatal smoking prevalence was indistinguishable from 0 . In fact, our estimates of $\beta_{1}$ were positive. The coefficient and standard error for $\beta_{1}$ in the prevalence models were 0.3136 and .3302 respectively. The same figures from the conditional smoking intensity model were 0.1041 and .2630 . Given Figure 4 and the large standard errors on our estimates, we infer that there is no discernible relationship between relative price changes in this set up. If anything, the positive coefficients may pick up a spurious relationship between changes in state 
excise taxes and prenatal smoking trends in the underlying state population. This casts doubt on the usefulness of treating state excise tax changes as exogenous.

\section{Conclusions}

In a study of over 9 million births before and after the MSA, the effect of the MSA on prenatal smoking was much smaller than expected. Based on repeated cross-sections of births during a period before and after the MSA, we estimated a $-2.65 \%$ change in prenatal smoking 15 months after the MSA. This estimate was less than $40 \%$ of the change one might expect given a price elasticity of prenatal smoking of -0.35 , the lowest national estimate reported in earlier studies (Evans and Ringel, 1999; Gruber and Köszegi, 2001; Gruber and Zinman, 2001; Ringel and Evans, 2001; Bradford, 2003; Colman et al., 2003; Lien and Evans, 2004). The difference between the observed change in prenatal smoking and the change implied by earlier estimates is even more remarkable given that cigarette prices continued to rise dramatically following the initial 45 cent price hike in November 1998, at least in part due to the MSA.

There are three plausible and potentially concurrent explanations that might reconcile our results with those in earlier studies. First, the composition of women who smoked during pregnancy during the time period we study may differ from women who smoked during earlier years. By 1997, there was wide public awareness of the health risks of smoking and rapidly rising cigarette prices. Prenatal smoking was falling rapidly in the early 1990's but the decline slowed in the years leading up to the MSA. Thus, the women still smoking during pregnancy in November 1998 may be particularly intransigent. This story is consistent with findings in Gruber and Köszegi (2001) and Gruber and Zinman (2001), where pregnant women showed less 
price response than when elasticities estimated using sales data, a measure of tobacco consumption overall. We think this offers a partial explanation of the results we observe.

A second explanation that reconciles our results with earlier studies is that previous studies in this area could be confounded by unobserved trends or policy changes within states. Most studies of the impact of tobacco prices on smoking have focused on changes in state tobacco excise taxes over time (Evans and Ringel, 1999; Gruber and Köszegi, 2001; Gruber and Zinman, 2001; Ringel and Evans, 2001; Colman et al., 2003). During certain time periods, excise tax increases have been endogenous with the environment of a given state. Kubik and Moran (2003), analyzing cigarette consumption data between 1955 and 1997 find that a state's tobacco excise taxes tend to go up in years following increases in the state's tobacco consumption.

Several other unmeasured state-level changes may have coincided with these tax increases, so that changes in prenatal smoking that were attributed exclusively to higher cigarette prices may actually have been caused by multiple factors. For example, legislators may have implemented tax changes as a response, at least in part, to changing attitudes towards smoking in their states. Furthermore, there may have been other tobacco control measures, such as restrictions on smoking in public places, which were implemented at the same time as the tax increases. Therefore, it is possible that the large price effects estimated in prior studies may be better attributed to a combination of changes in attitudes, policies, and prices. Indeed, Lien and Evans (2004) deliberately interpret their results as evidence of a response to all anti-tobacco policy and not just a price response.

Finally, most of the earlier studies (Evans and Ringel, 1999; Gruber and Köszegi, 2001; Gruber and Zinman, 2001; Ringel and Evans, 2001; Bradford, 2003; Colman et al., 2003) analyzed the effects of small changes in state taxes or prices. It may not be appropriate to 
extrapolate the effects of incremental changes to cases of large price increases. Lien and Evans (2004) focus their work on larger tax changes in four states, and their elasticity estimates were highly variable across states, ranging from -0.10 in Illinois to -1.82 in Massachusetts.

At first glance, our findings seem discrepant with national cigarette sales data in the immediate wake of the MSA. Estimates by Cutler et al. (2002) suggest that national cigarette sales fell by $6.5 \%$ in the year following the MSA, which implies a demand elasticity of -0.33 , within the range of prior elasticity estimates. However, in Figure 5 we present smoking rates for women of child bearing age, older women, and all men from the National Health Interview Survey between 1997 and 2000. These data show that at the time of the MSA, 1998-1999, smoking rates dropped substantially for everyone but women of childbearing age. Both our estimates and those of Cutler et al. are consistent with the NHIS data in Figure 5.

Although the MSA had a smaller than expected effect on smoking for most pregnant women, we found the greatest reductions in prenatal smoking following the MSA occurred among teenage mothers. Preventing smoking initiation among the young is believed by many to be the most effective way to reduce smoking-related morbidity and mortality in the long term (USDHHS, 1994; Wechsler et al., 1998; Bauer et al., 2000; Gruber and Zinman, 2001). Even if, as some suggest, increasing prices delays rather than prevents teen smoking (Glied, 2002), short term price-induced reductions in teen smoking may have important consequences for birth weight outcomes.

Our study has several limitations. First, because the post-MSA price increase was nationwide, no control group was available. However, secular trends in prenatal smoking would have to have shifted dramatically upwards before our estimate of the relative change in prenatal smoking 15 months after the MSA reached $-7.4 \%$. In addition, we believe the most likely non- 
price factor concurrent with the MSA that would also have affected smoking is negative publicity about both smoking and the tobacco industry, a factor which would reduce smoking. Any non-price factors that decreased tobacco use would suggest that the price effect is even smaller than what we have estimated.

Second, maternal self-reports of smoking on birth certificates may be inaccurately low due to social desirability bias. Colman et al. (2003) show that the Natality Detail Files have lower reported smoking prevalence than the PRAMS database. Even if there were untruthful reports of prenatal smoking status, our results will not be biased provided such inaccuracies are not associated with price-responsiveness or time period. We have no reason to believe the accuracy of self-reported smoking changed substantially between earlier studies using the Natality Detail Files (Evans and Ringel, 1999; Gruber and Köszegi, 2001; Gruber and Zinman, 2001; Ringel and Evans, 2001; Lien and Evans, 2004) and this study, nor that the accuracy of self-reported smoking changed during the course of the this study.

Lastly, several states, constituting approximately $20 \%$ of births in the United States population, were excluded. Our findings may not be representative of those populations. Four percent of the women meeting our selection criteria were excluded because of missing data. As missingness was similar before and after the MSA for all variables, it is not expected to bias our results with respect to the impact of the MSA.

In summary, the sharp rise in cigarette prices following the MSA had little effect on smoking prevalence and intensity among most pregnant women, but the effect was slightly stronger among pregnant teenagers. The overall modest change in tobacco use in response to a large change in cigarette prices differs markedly from those implied by earlier estimates of the price elasticity of smoking among pregnant women. Cigarette taxes are widely viewed as the 
most effective means of reducing tobacco use, capitalizing on the price-responsiveness of smokers. The 2000 Surgeon General's Report states that, relative to other interventions, taxation both reaches more individuals and has a greater effect (USDHHS, 2000). Policy makers should be aware that not all populations of smokers, and therefore not all smoking-related illnesses, will be affected equally by cigarette price increases. Our findings suggest that among pregnant women, excise taxes are less effective than previously believed. 


\section{REFERENCES}

American Legacy Foundation, 2004. Accessed at

http://www.americanlegacy.org/americanlegacy/skins/alf/display.aspx?Action=display_p $\underline{\text { age } \& \text { mode }=\text { User\&ModuleID }=8 \mathrm{cde} 2 \mathrm{e} 88-3052-448 \mathrm{c}-893 \mathrm{~d}-}$ $\underline{\mathrm{d} 0 \mathrm{~b} 4 \mathrm{~b} 14 \mathrm{~b} 31 \mathrm{c} 4 \& \text { ObjectID=5441ae49-f8bb-4a52-9c7c-fed6a573fe48. }}$.

Bauer, U.E., Johnson, T.M., Hopkins, R.S., Brooks, R.G., 2000. Changes in youth cigarette use and intentions following implementation of a tobacco control program: findings from the Florida Youth Tobacco Survey, 1998-2000. Journal of the American Medical Association 284(6), 723-728.

Bradford, W., 2003. Pregnancy and the demand for cigarettes. American Economic Review 93, $1752-1763$.

Capehart, T., 2001. Trends in the cigarette industry after the Master Settlement Agreement. USDA-ERS Publication \#TBS-250-1, Economic Research Service, US Department of Agriculture, Washington, DC.

Chaloupka, F.J., Pacula, R.L., 1999. Sex and race differences in young people's responsiveness to price and tobacco control policies. Tobacco Control 8(4), 373-377.

Chaloupka, F.J., Warner, K.E., 2000, The Economics of Smoking. In: Newhouse, J.P., Culyer , A.J. (Eds.), The Handbook of Health Economics. North-Holland, Amsterdam, pp. 15391627.

Colman, G., Grossman, M., Joyce, T., 2003. The effect of cigarette excise taxes on smoking before, during, and after pregnancy. Journal of Health Economics 22, 1053-1072. 
Cutler, D., Gruber, J., Hartman, R., Landrum, M., Newhouse, J., Rosenthal, M., 2002. The Economic Impacts of the Tobacco Settlement. Journal of Policy Analysis and Management 21, 1-19.

Evans, W.N., Ringel, J.S., 1999. Can higher cigarette taxes improve birth outcomes? Journal of Public Economics 72, 135-154.

Farrelly, M., Bray, J., 1998. Response to increases in cigarette prices by race/ethnicity, income, and age groups--United States, 1976-1993. Morbidity \& Mortality Weekly Report 47(29), 605-609.

Glied, S., 2002. Youth tobacco control: reconciling theory and empirical evidence. Journal of Health Economics 21(1), 117-135.

Gruber, J., Köszegi, B., 2001. Is Addiction "Rational"? Theory and Evidence. The Quarterly Journal of Economics 116(4), 1261-1303.

Gruber, J., Zinman, J., 2001, Youth Smoking in the United States. In: Gruber, J. (Ed.), Risky Behaviors Among Youths: An Economic Analysis. University of Chicago Press, Chicago, pp. 69-120.

Hu, T.W., Ren, Q.F., Keeler, T.E., Bartlett, J., 1995. The demand for cigarettes in California and behavioural risk factors. Health Economics 4(1), 7-14.

Kubik, J.D., Moran, J.R., 2003. Can policy changes be treated as natural experiments? Evidence from cigarette excise taxes. Syracuse University Working Paper.

Lewitt, E.M., Coate, D., 1982. The potential for using excise taxes to reduce smoking. Journal of Health Economics 1(2), 121-145.

Lien, D., Evans, W., 2004. Estimating the impact of large cigarette tax hikes: The case of maternal smoking and infant birth weight. Journal of Human Resources Forthcoming. 
National Vital Statistics Section, National Center for Health Statistics, 1996-2000. Natality Detail Files. Accessed at http://www.cdc.gov/nchs/products/elec_prods/subject/natality.htm.

National Center for Health Statistics, 1998, Vital statistics of the United States. US Department of Health and Human Services, National Center for Health Statistics.

National Center for Health Statistics, 2003, Health, United States, 2003 With Chartbook on Trends in the Health of Americans. US Department of Health and Human Services, Centers for Disease Control and Prevention, National Center for Health Statistics, pp. 109.

National Center for Health Statistics, 2004. Health, United States, 2004 With Chartbook on Trends in the Health of Americans. US Department of Health and Human Services, Centers for Disease Control and Prevention, National Center for Health Statistics, Hyattsville, MD.

Orzechowski and Walker, 2003. The Tax Burden on Tobacco: Historical Compilation. Volume 37, 2002, Arlington, VA.

Ringel, J.S., Evans, W.N., 2001. Cigarette taxes and smoking during pregnancy. American Journal of Public Health 91(11), 1851-1856.

Schroeder, S.A., 2004. Tobacco control in the wake of the 1998 master settlement agreement. New England Journal of Medicine 350(3), 293-301.

U.S. Department of Agriculture, 2004. Wholesale premium brand cigarette price revisions, 19902004. Accessed at http://www.ers.usda.gov/Briefing/Tobacco/Data/table09.pdf.

U.S. Department of Health and Human Services, 1990. The health benefits of smoking cessation: a report of the Surgeon General. Public Health Service, Centers for Disease Control and 
Prevention, National Center for Chronic Disease Prevention and Health Promotion, Office on Smoking and Health, Rockville, MD.

U.S. Department of Health and Human Services, 1994. Preventing Tobacco Use Among Young People: A Report of the Surgeon General. Public Health Service, Centers for Disease Control and Prevention,, National Center for Chronic Disease Prevention and Health Promotion, Office on Smoking and Health, Rockville, MD.

U.S. Department of Health and Human Services, 2000. Reducing Tobacco Use: A Report of the Surgeon General. Public Health Service, Centers for Disease Control and Prevention,, National Center for Chronic Disease Prevention and Health Promotion, Office on Smoking and Health, Rockville, MD.

U.S. Department of Health and Human Services, 2001. Women and smoking: a report of the Surgeon General. Public Health Service, Centers for Disease Control and Prevention,, National Center for Chronic Disease Prevention and Health Promotion, Office on Smoking and Health, Rockville, MD.

U.S. Department of Labor, 2003. Consumer Price Index - All Urban Consumers - (CPI-U) - US City Average. Accessed September 24, 2003 at ftp://ftp.bls.gov/pub/special.requests/cpi/cpiai.txt.

Wasserman, J., Manning, W.G., Newhouse, J.P. Winkler, J.D., 1991. The effects of excise taxes and regulations on cigarette smoking. Journal of Health Economics 10(1), 43-64.

Wechsler, H., Rigotti, N.A., Gledhill-Hoyt, J. Lee, H., 1998. Increased levels of cigarette use among college students: a cause for national concern. Journal of the American Medical Association 280(19), 1673-1678. 
White, H., 1980. A heteroskedasticy consistent covariance matrix estimator and a direct test for heteroskedasticy. Econometrica 48, 817-830. 


\section{Table 1. Summary Statistics for Final Study Population with Complete Records}

\begin{tabular}{|c|c|c|c|}
\hline Outcomes & Pre-MSA* & Post-MSA* & $\%$ Missing $\dagger$ \\
\hline Self-reported smoking (\%) & 12.6 & 11.5 & 1.2 \\
\hline Self-reported number of cigarettes/day, mean (sd) & $11.3(7.5)$ & $10.6(7.1)$ & 1.7 \\
\hline \multicolumn{4}{|l|}{ Covariates } \\
\hline \multicolumn{4}{|l|}{ Real Federal + state cigarette excise tax at time of } \\
\hline conception, mean (sd), 1999\$ & $0.62(0.21)$ & $0.64(0.24)$ & 0.0 \\
\hline Race/Ethnicity (\%) & & & 0.0 \\
\hline White & 65 & 62 & \\
\hline Black & 16 & 16 & \\
\hline Hispanic & 14 & 16 & \\
\hline Other (includes unknown, not stated) & 5 & 5 & \\
\hline Educational Attainment (\%) & & & 1.5 \\
\hline$<$ High School & 5 & 5 & \\
\hline Some High School & 16 & 16 & \\
\hline High School & 33 & 33 & \\
\hline Some College & 23 & 22 & \\
\hline College or Higher & 24 & 25 & \\
\hline Age $(\%)$ & & & $0.0 \dagger$ \\
\hline $15-19$ & 13 & 12 & \\
\hline $20-24$ & 25 & 26 & \\
\hline $25-29$ & 28 & 27 & \\
\hline $30-34$ & 22 & 22 & \\
\hline $35-39$ & 10 & 11 & \\
\hline
\end{tabular}


Table 1. Summary Statistics for Study Population with Complete Records (cont.)

\begin{tabular}{|c|c|c|c|}
\hline Covariates & Pre-MSA* & Post-MSA* & $\%$ Missing $\dagger$ \\
\hline $40-44$ & 2 & 2 & \\
\hline Parity $(\%)$ & & & 0.7 \\
\hline $1^{\text {st }}$ child & 34 & 33 & \\
\hline $2^{\text {nd }}$ child & 30 & 30 & \\
\hline $3^{\text {rd }}$ child & 19 & 19 & \\
\hline $4^{\text {th }}$ child or greater & 17 & 18 & \\
\hline Trimester Prenatal Care Began (\%) & & & 0.0 \\
\hline Received No Prenatal Care & 1 & 1 & \\
\hline $1^{\text {st }}$ & 83 & 83 & \\
\hline $2^{\text {nd }}$ & 13 & 13 & \\
\hline $3^{\text {rd }}$ & 3 & 3 & \\
\hline Number of Prenatal Care Visits (\%) & & & 3.6 \\
\hline 0 Visits & 1 & 1 & \\
\hline $1^{\text {st }}$ Quartile (1-10 Visits) & 35 & 36 & \\
\hline $2^{\text {nd }}$ Quartile (11-12 Visits) & 27 & 27 & \\
\hline $3^{\text {rd }}$ Quartile (13-14 Visits) & 18 & 17 & \\
\hline $4^{\text {th }}$ Quartile ( $\geq 15$ Visits $)$ & 18 & 18 & \\
\hline Mother is Married (\%) & 68 & 67 & 0.0 \\
\hline Previous Preterm Birth (\%) & 1 & 1 & 1.5 \\
\hline $\begin{array}{l}\text { Self-Reported Heavy Drinking ( } \geq 5 \text { Drinks/week) } \\
(\%)\end{array}$ & 0.12 & 0.09 & 1.8 \\
\hline Infant Sex is Female (\%) & 49 & 49 & 0.0 \\
\hline
\end{tabular}

*Some proportions do not total exactly $100 \%$ due to rounding.

† Given state, age, and gestational age are known. 
Table 2. Selected Pre-Post Regression Model Coefficients (Standard Errors) for the Overall Study Population

\begin{tabular}{|c|c|c|c|c|}
\hline & \multicolumn{2}{|c|}{ Smoking Prevalence } & \multicolumn{2}{|c|}{ Conditional Smoking Intensity } \\
\hline \multicolumn{5}{|l|}{ MSA Effects } \\
\hline Time & -0.000104 & $(0.000040)^{*}$ & -0.012 & $(0.0014)^{* *}$ \\
\hline Post-MSA & -0.003169 & $(0.001110)^{*}$ & -0.186 & $(0.0357)^{* *}$ \\
\hline Time*Post-MSA & 0.000004 & $(0.000058)$ & -0.008 & $(0.0035)^{*}$ \\
\hline Real Federal + state excise taxes & -0.000099 & $(0.000034)^{*}$ & -0.001 & $(0.0015)$ \\
\hline \multicolumn{5}{|l|}{ Race/Ethnicity (White is reference) } \\
\hline Black & -0.159148 & $(0.009081)^{* *}$ & -4.368 & $(0.1283)^{* *}$ \\
\hline Hispanic & -0.179999 & $(0.008374)^{* *}$ & -3.924 & $(0.3338)^{* *}$ \\
\hline \multicolumn{5}{|l|}{ Other (includes unknown, not } \\
\hline stated) & -0.077625 & $(0.008266)^{* *}$ & -1.856 & $(0.3439)^{* *}$ \\
\hline \multicolumn{5}{|c|}{ Educational Attainment $(<$ High School is reference) } \\
\hline Some High School & 0.082633 & $(0.011890)^{* *}$ & -0.973 & $(0.0888)^{* *}$ \\
\hline High School & -0.014728 & $(0.008290)$ & -1.885 & $(0.1205)^{* *}$ \\
\hline Some College & -0.081653 & $(0.009666)^{* *}$ & -2.769 & $(0.1392)^{* *}$ \\
\hline College or Higher & -0.143299 & $(0.010942)^{* *}$ & -4.095 & $(0.1738)^{* *}$ \\
\hline \multicolumn{5}{|l|}{ Age (15-19 is reference) } \\
\hline $20-24$ & 0.047342 & $(0.005507)^{* *}$ & 1.194 & $(0.0324)^{* *}$ \\
\hline $25-29$ & 0.042823 & $(0.006033)^{* *}$ & 1.945 & $(0.0411)^{* *}$ \\
\hline $30-34$ & 0.036396 & $(0.005813)^{* *}$ & 2.432 & $(0.0562)^{* *}$ \\
\hline $35-39$ & 0.039138 & $(0.006145)^{* *}$ & 2.935 & $(0.0699)^{* *}$ \\
\hline $40-44$ & 0.026029 & $(0.005703)^{* *}$ & 3.541 & $(0.0891)^{* *}$ \\
\hline
\end{tabular}




\section{Table 3. Model-Based Predictions of Prenatal Smoking Prevalence $\dagger$}

\section{Months After the MSA}

\begin{tabular}{cccccc}
\hline Population & $\begin{array}{c}\text { Without MSA } \\
\text { (Secular Trend Only) }\end{array}$ & With MSA & \multicolumn{2}{c}{$\begin{array}{c}\text { Relative Difference } \\
(95 \% \text { confidence interval) }\end{array}$} & Elasticity \\
\hline All & $11.40 \%$ & $11.08 \%$ & $-2.75 \%$ & $(-4.79 \% \text { to }-0.72 \%)^{*}$ & -0.13 \\
\hline White & 14.35 & 14.06 & -2.05 & $(-4.03 \text { to }-0.06)^{*}$ & -0.10 \\
\hline Black & 8.18 & 8.03 & -1.83 & $(-5.81$ to 2.15$)$ & -0.09 \\
\hline Hispanic & 3.32 & 3.13 & -5.65 & $(-12.92$ to 1.61$)$ & -0.27 \\
\hline$\leq$ HS education & 17.60 & 17.16 & -2.49 & $(-4.54 \text { to }-0.43)^{*}$ & -0.12 \\
\hline$>$ HS education & 4.82 & 4.71 & -2.35 & $(-6.20$ to 1.51$)$ & -0.11 \\
\hline 15-19 years old & 18.01 & 16.87 & -6.32 & $(-8.93 \text { to }-3.70)^{* *}$ & -0.30 \\
\hline 20-44 years old & 10.51 & 10.31 & -1.87 & $(-3.98$ to 0.24$)$ & -0.09 \\
\hline
\end{tabular}

15 Months After the MSA

\begin{tabular}{|c|c|c|c|c|c|}
\hline & $\begin{array}{c}\text { Without MSA } \\
\text { (Secular Trend Only) }\end{array}$ & With MSA & $\begin{array}{r}\mathrm{R} \\
(95 \%\end{array}$ & $\begin{array}{l}\text { lative Difference } \\
\text { confidence interval) }\end{array}$ & Elasticity \\
\hline All & $11.74 \%$ & $11.43 \%$ & $-2.65 \%$ & $(-4.96 \% \text { to }-0.34 \%)^{*}$ & -0.13 \\
\hline White & 15.35 & 15.08 & -1.78 & $(-3.95$ to 0.40$)$ & -0.08 \\
\hline Black & 8.57 & 8.50 & -0.80 & $(-5.41$ to 3.80$)$ & -0.04 \\
\hline Hispanic & 3.11 & 2.95 & -5.08 & $(-14.79$ to 4.64$)$ & -0.24 \\
\hline$\leq$ HS education & 17.39 & 16.96 & -2.51 & $(-5.03$ to 0.01$)$ & -0.12 \\
\hline$>$ HS education & 5.13 & 5.04 & -1.62 & $(-6.22$ to 2.98$)$ & -0.08 \\
\hline $15-19$ years old & 17.82 & 16.33 & -8.38 & $(-11.45 \text { to }-5.31)^{* *}$ & -0.40 \\
\hline 20-44 years old & 10.92 & 10.78 & -1.28 & $(-3.65$ to 1.09$)$ & -0.06 \\
\hline \multicolumn{6}{|c|}{$\dagger$ All estimates adjusted for covariates in Table 1.} \\
\hline
\end{tabular}




\section{Table 4. Model-Based Predictions of Prenatal Smoking Intensity (Cigarettes/Day) †}

\section{Months After the MSA}

\begin{tabular}{lccccc}
\hline $\begin{array}{l}\text { Population } \\
\text { All }\end{array}$ & $\begin{array}{c}\text { Without MSA } \\
\text { (Secular Trend Only) }\end{array}$ & With MSA & \multicolumn{2}{c}{$\begin{array}{c}\text { Relative Difference } \\
(95 \% \text { confidence interval) }\end{array}$} & Elasticity \\
\hline White & 10.7 & 10.5 & $-2.32 \%$ & $(-3.13 \% \text { to }-1.50 \%)^{* *}$ & -0.11 \\
\hline Black & 11.3 & 11.1 & -2.21 & $(-2.97 \text { to }-1.44)^{* *}$ & -0.11 \\
\hline Hispanic & 8.1 & 7.9 & -3.12 & $(-5.56 \text { to }-0.68)^{*}$ & -0.15 \\
\hline - HS education & 7.5 & 7.3 & -1.96 & $(-6.29$ to 2.37$)$ & 0.09 \\
\hline$>$ HS education & 11.0 & 10.7 & -2.44 & $(-3.32 \text { to }-1.55)^{* *}$ & -0.12 \\
\hline 15-19 years old & 10.0 & 9.8 & -1.86 & $(-3.19 \text { to }-0.54)^{*}$ & -0.09 \\
\hline 20-44 years old & 9.3 & 9.0 & -3.04 & $(-5.03 \text { to }-1.06)^{* *}$ & -0.14 \\
\hline
\end{tabular}

15 Months After the MSA

\begin{tabular}{lccccc}
\hline & $\begin{array}{c}\text { Without MSA } \\
\text { (Secular Trend Only) }\end{array}$ & With MSA & $\begin{array}{c}\text { Relative Difference } \\
(95 \% \text { confidence interval) }\end{array}$ & Elasticity \\
\hline All & 10.8 & 10.5 & $-2.82 \%$ & $(-3.95 \% \text { to }-1.69 \%)^{* *}$ & -0.13 \\
\hline White & 11.4 & 11.1 & -2.73 & $(-3.78 \text { to }-1.68)^{* *}$ & -0.13 \\
\hline Black & 8.0 & 7.8 & -3.12 & $(-6.74$ to 0.50$)$ & -0.15 \\
\hline Hispanic & 7.3 & 7.2 & -1.83 & $(-7.73$ to 4.07$)$ & -0.09 \\
\hline$\leq$ HS education & 10.9 & 10.6 & -2.84 & $(-4.11 \text { to }-1.58)^{* *}$ & -0.14 \\
\hline$>$ HS education & 10.1 & 9.8 & -2.78 & $(-4.36 \text { to }-1.20)^{* *}$ & -0.13 \\
\hline 15-19 years old & 9.3 & 9.0 & -3.34 & $(-5.98 \text { to }-0.70)^{*}$ & -0.16 \\
\hline 20-44 years old & 11.1 & 10.8 & -2.74 & $(-3.78 \text { to }-1.71)^{* *}$ & -0.13 \\
\hline All estimates adjusted for covariates in Table 1. & & & & \\
\hline
\end{tabular}


Figure 1. Inflation-adjusted Retail and Wholesale Cigarette Prices, Including Excise Taxes, November 1995 to April 2000

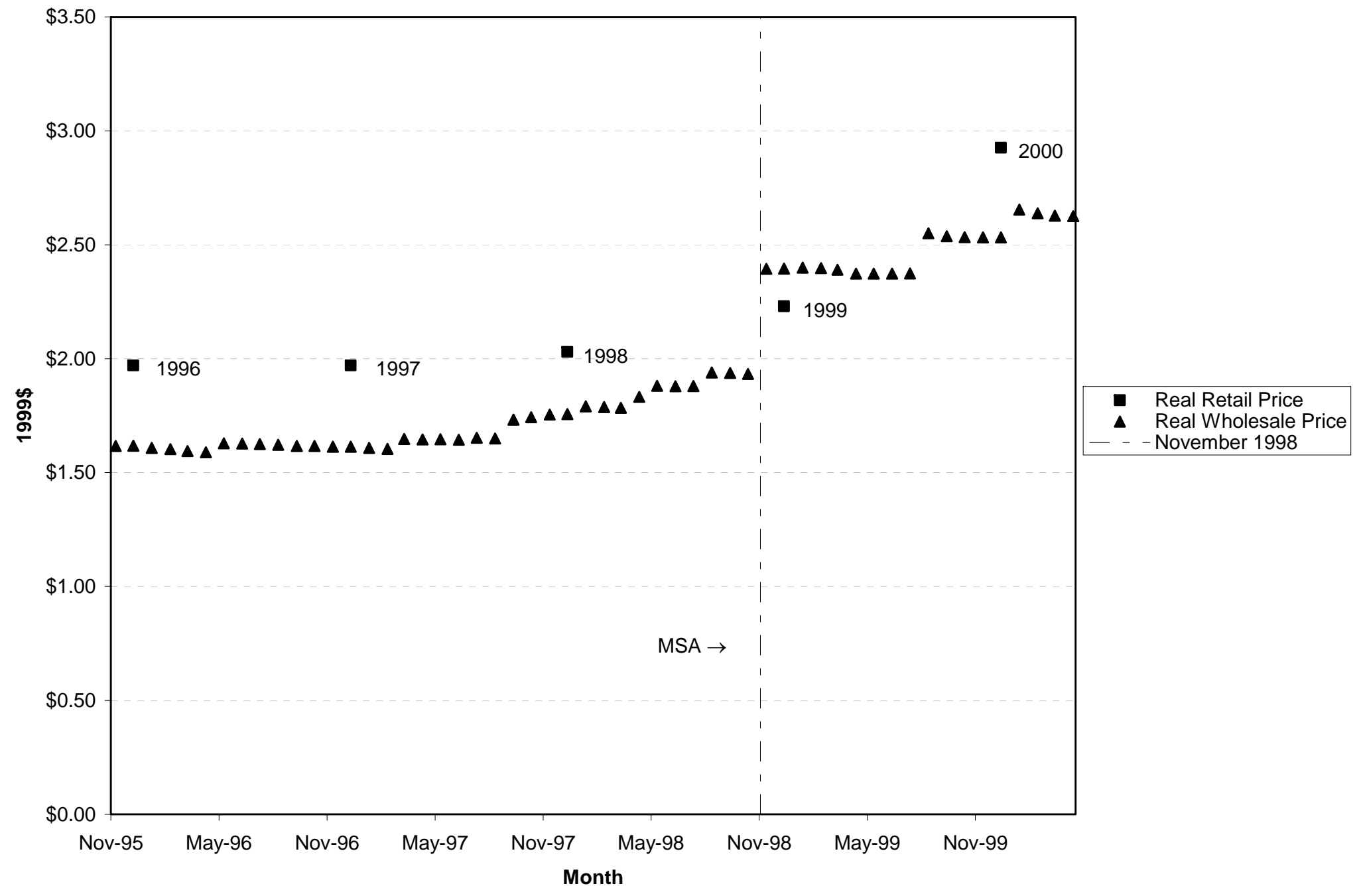


Figure 2. Cigarette Smoking During Pregnancy 1989-2001 (NCHS, 2004)

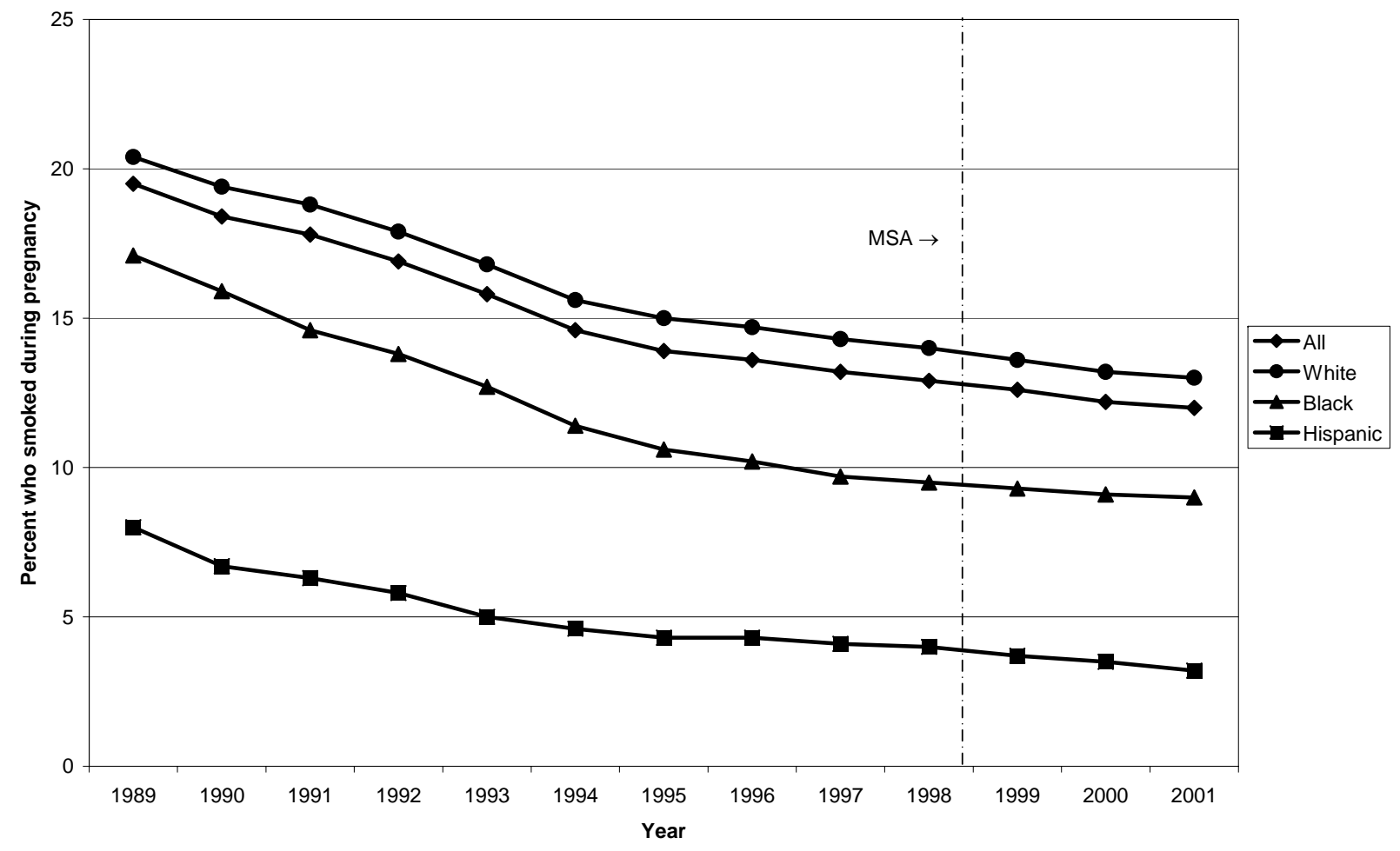


Figure 3. Unadjusted and Regression-Adjusted Prenatal Smoking Prevalence With and Without the MSA, January 1996 to February 2000

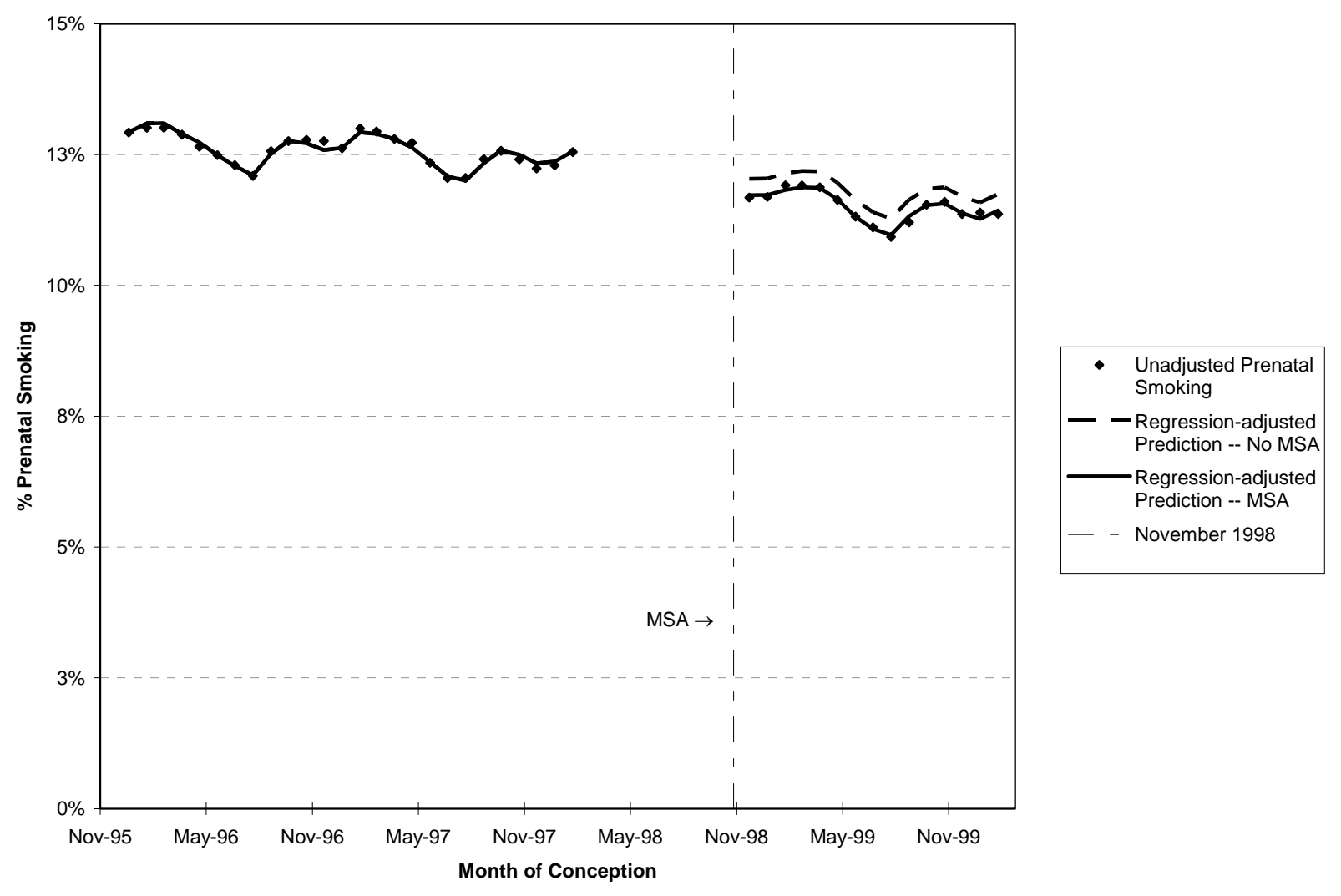


Figure 4. Relative Changes in Smoking Prevalence as a Function of Relative Price Changes, FY1998 to FY2000

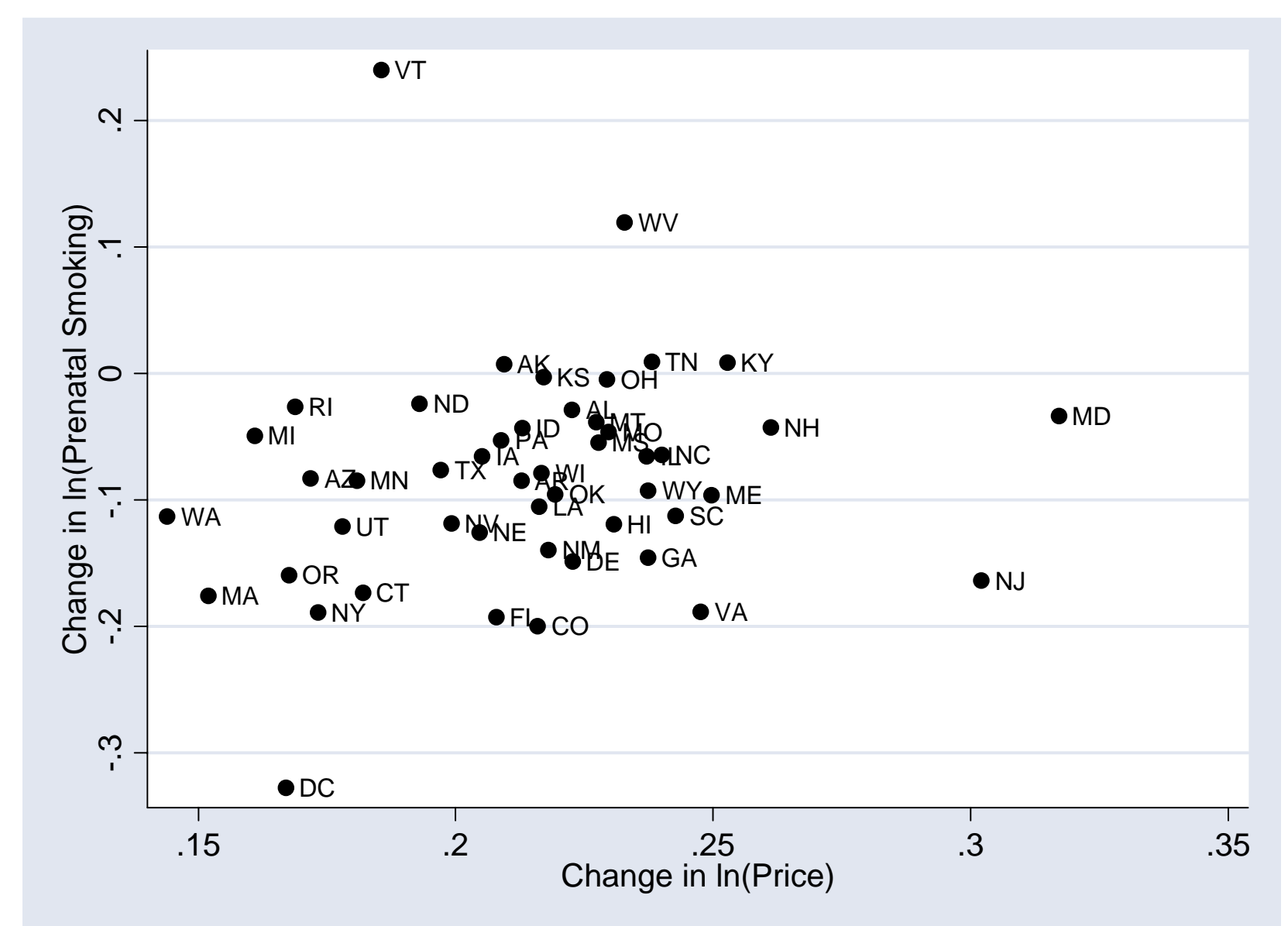


Figure 5. Population Smoking Prevalence by Age and Sex, National Health Interview Survey, 1997-2001

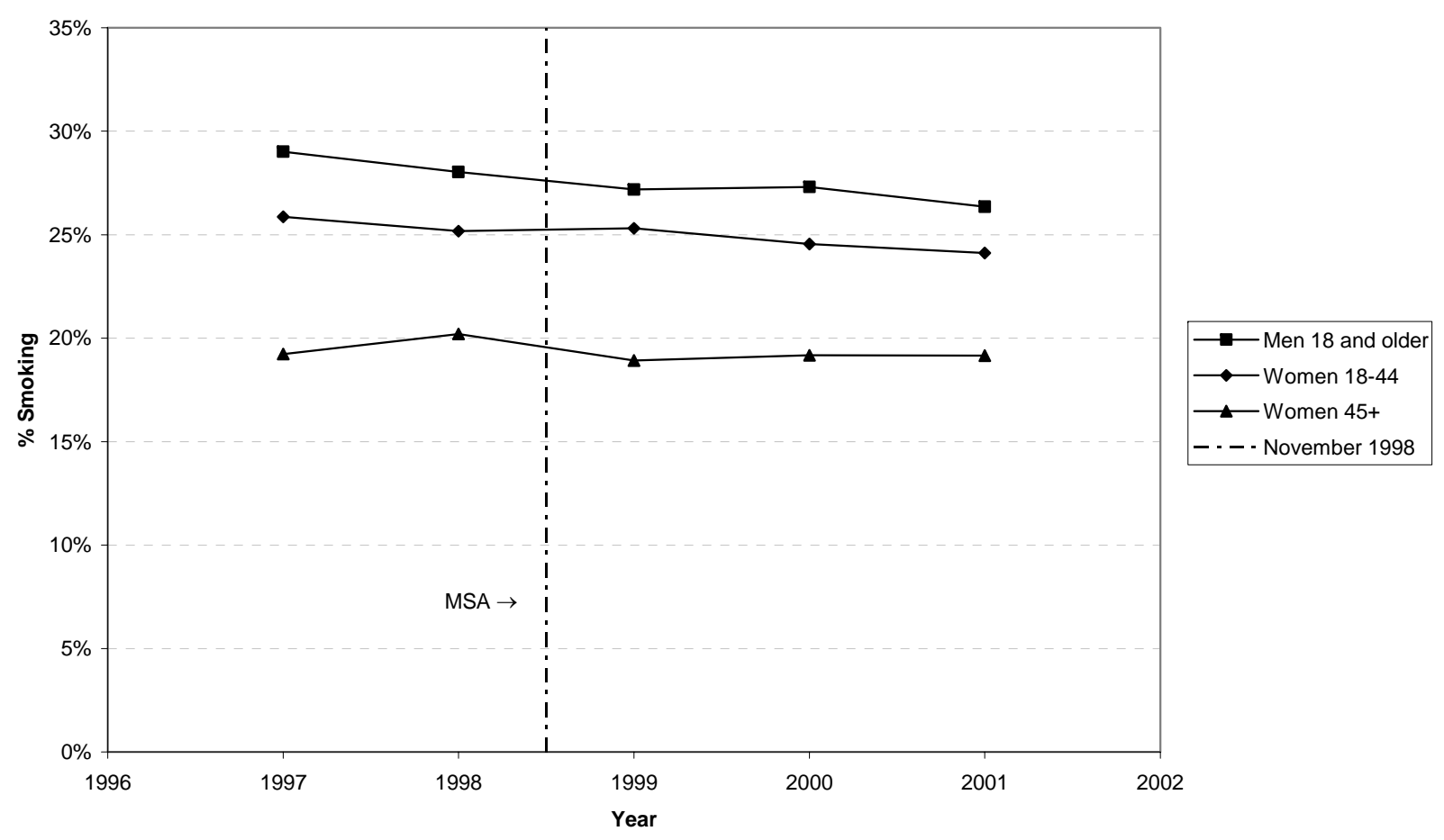

